\title{
Expression of the GLI family genes is associated with tumor progression in advanced lung adenocarcinoma
}

\author{
Masashi Ishikawa*, Makoto Sonobe, Naoto Imamura, Terumasa Sowa, Kei Shikuma and Hiroshi Date
}

\begin{abstract}
Background: The hedgehog $(\mathrm{Hh})$ signaling pathway is aberrantly activated in various cancers. Expression of the GLI family of genes, which encode for transcriptional factors of the Hh pathway, has not been fully assessed in clinical samples of advanced lung adenocarcinoma. In this study, we retrospectively evaluated the expression of the GLI family of genes in advanced stage lung adenocarcinoma samples and determined their relation to patient survival.

Methods: The levels of GLI1, GLI2, and GLI3 mRNA expression were measured by quantitative real-time polymerase chain reaction in surgically obtained tissue samples from stage II-IV lung adenocarcinoma patients $(n=102)$. Pairwise comparisons between all three GLI mRNA expression were performed, and after dichotomizing the patients into low and high expression groups according to each GLI mRNA expression level, survival curves were calculated and multivariate analyses were conducted.

Results: Significant positive correlation was found between $G L / 1$ and $G L / 3$ mRNA expression $(P<0.001)$. Tumors with higher expression (upper 15\%) of GL/1 or GLI3 mRNA were associated with poor survival in stage II-IV (5-year overall survival rates: GLI1 mRNA low, 41.7\% vs. high, 20.0\%, $P=0.0074$; GLI3 mRNA low, 43.1\% vs. high, 13.3\%, $P=0.0062$ ) and stage III-IV (5-year overall survival rates: GLI1 mRNA low, 34.0\% vs. high, 0\%, $P=0.0012 ;$;LI3 mRNA low, 33.4\% vs. high, $7.7 \%, P=0.057$ ) lung adenocarcinoma patients. GLI2 mRNA expression did not appear to have great clinical significance. Multivariate analysis revealed higher GL/1 mRNA expression as an independent factor for unfavorable patient survival $(P=0.0030$, hazard ratio $=3.1,95 \%$ confidence interval $=1.5-6.2)$, as well as tumor differentiation and stage.

Conclusions: Expression of GLI1 and GLI3 mRNA was strongly correlated, and their overexpression, especially that of GLII, was found to be predictive of aggressive tumor behavior. This study indicates that the Hh pathway may be a key oncogenic signaling network in tumor pathogenesis and, thus, a potential therapeutic target in advanced lung adenocarcinoma.
\end{abstract}

Keywords: GLI, Hedgehog signaling, Lung adenocarcinoma, Advanced stage, Expression, Prognosis

\section{Background}

Non-small cell lung cancer (NSCLC) has been the leading cause of cancer-related deaths world-wide, and adenocarcinoma accounts for the majority of all NSCLC cases $[1,2]$. Although any possibility of a cure rests almost entirely with surgical resection with or without chemo- or radiotherapy, postoperative recurrence rate is still high and survival rate remains low compared with other types of cancers. In particular, advanced NSCLC can be

\footnotetext{
* Correspondence: mishi@kuhp.kyoto-u.ac.jp

Department of Thoracic Surgery, Faculty of Medicine, Kyoto University, 54 Shogoin-kawaharacho, Sakyo-ku, Kyoto 606-8507, Japan
}

exceptionally lethal even with aggressive anticancer therapies, despite the dramatic treatment shift of some targeted therapeutic agents for lung adenocarcinoma [3,4]. Developing and deploying new treatment approaches are vital to improve patient prognoses.

The hedgehog $(\mathrm{Hh})$ signaling pathway, which consists of three distinct homologues (sonic, indian, and desert Hh) is constitutively activated in a variety of human tumor entities [5]. Normally, Hh signaling plays an important role during vertebral embryonic development and tissue maintenance [6]. The Hh proteins are secreted molecules, and their receptor, Patched, usually functions as a downstream 
inhibitor in the absence of $\mathrm{Hh}$. Hh signaling is activated through binding to the Patched receptor, which unleashes the transmembrane protein, Smoothened, and ultimately upregulates GLI [5]. GLI proteins are zinc finger transcription factors which exert their functions by nuclear localization and promoting target gene transcription, and in humans, at least three distinct GLI genes, GLI1, GLI2, and GLI3, have been identified [7]. As the GLI family of proteins are the final mediators of Hh signaling, their expression, especially that of GLI1, is deemed to be the best reflection of the net effect of $\mathrm{Hh}$ activation, thus, survival studies on GLI may indicate the potential involvement of $\mathrm{Hh}$ in tumor pathogenesis [8].

In addition to the tumorigenesis based on genetic alterations of the Hh pathway predominantly seen in basal cell carcinoma and medulloblastoma, extensive involvement of ligand-dependent $\mathrm{Hh}$ activation has been suggested in various cancer entities $[9,10]$. With regard to lung cancer, while the involvement of $\mathrm{Hh}$ signaling in small cell lung cancer has been shown to be evident [11-13], it remains poorly understood in lung adenocarcinoma, especially in the advanced stages.

In this study, we evaluated the expression levels of the three GLI family genes (GLI1, GLI2, and GLI3) in surgical samples from advanced lung adenocarcinoma patients (stage II-IV), and revealed the possible involvement of the Hh signaling pathway in tumor advancement by analysis for correlations between GLI expression and patient prognosis. As we found considerable impact of GLI1 and GLI3 gene expression on patient survival, this study demonstrates that inhibition of Hh signaling may be a promising drug target for the treatment of advanced lung adenocarcinoma.

\section{Methods}

Patients, tissue samples, and tumor information

Tissue samples were obtained from patients who were diagnosed as stage II-IV lung adenocarcinoma after surgical resection at the Kyoto University Hospital between July 2001 and December 2007. Continuous surgical cases with sufficient tissue material for evaluations were included in this study $(\mathrm{n}=102)$. All of these tumors were histologically confirmed as lung adenocarcinoma, and their tumor staging and degree of differentiation were all assessed by board-certified pathologists in the Department of Pathology of the Kyoto University Hospital. Tumor stage was determined by the latest tumor-node-metastasis classification system [14]. Histological type and grade of cell differentiation were determined according to the WHO classification system [15]. Their demographics and baseline characteristics are presented in Table 1 . Pre- or postoperative chemotherapy was mainly composed of orally administered tegafur-uracil and/or conventional intravenous chemotherapeutic agents (carboplatin, paclitaxel, docetaxel, gemcitabine, vinorelbine) for NSCLC. Only one patient (stage II) received radiotherapy prior to surgery (concurrently with chemotherapy), and postoperative radiotherapy (mediastinum or chest wall) was performed in four patients (stage III). Complete tumor resection was achieved in 77 patients (75.5\%), whereas in 25 patients (24.5\%) macro- or microscopic residual tumors were suspected after surgery (for example, pleural dissemination, malignant pleural effusion, positive stumps, or distant metastasis prior to surgery). Informed consent for participation in this study was obtained from all patients prior to their surgeries, and this study was reviewed and approved by the Ethics Committee of the Graduate School and Faculty of Medicine at the Kyoto University.

\section{Preparation of tissue mRNA}

For sample collection, tumor tissue samples were dissected immediately after surgical resection and soaked in RNAlater TissueProtect Tubes (Qiagen, Tokyo, Japan) for more than $48 \mathrm{~h}$ before storage at $-80^{\circ} \mathrm{C}$ until use. Total RNA was isolated from tissue samples using RNeasy Plus Mini Kit (Qiagen), and reverse transcription of total RNA was conducted using the Ready-To-Go You-Prime FirstStrand Beads (Amersham Biosciences, Uppsala, Sweden) to obtain cDNA.

\section{Quantification of GLI mRNA}

To quantify GLI mRNA expression levels of each sample, quantitative real-time PCR was performed using the LightCycler thermal cycler system (Roche Diagnostics Japan, Tokyo, Japan). The PCR primers used for the quantitative amplification of GLI1 mRNA were forward: 5' - CTCCCGAAGGACAGGTATGTAAC - 3' and reverse: 5' - CCCTACTCTTTAGGCACTAGAGTTG -3', those of GLI2 mRNA were forward: 5' - AGAAGCAGCGCAAT GACGTG -3' and reverse: 5' - GTCATCCAGTGCCGT CAGGT - 3 ', and those of GLI3 mRNA were forward: 5' AAACCCCAATCATGGACTCAAC $-3^{\prime}$ and reverse: $5^{\prime}-$ TACGTGCTCCATCCATTTGGT-3'. The primers for glyceraldehyde-3-phosphate dehydrogenase (GAPDH) mRNA, used as an internal control, were forward: 5'-ACAACAGCCTCAAGATCATCAG-3' and reverse: 5'-TCTTCTGGGTGGCAGTGATG-3'. After a $20-\mu \mathrm{L}$ reaction mixture containing $0.5 \mu \mathrm{M}$ forward/reverse primers and $0.03 \mu \mathrm{g}$ cDNA in QuantiTect SYBR Green PCR Master Mix (Qiagen) was prepared, PCR amplification was initiated by preincubation for $15 \mathrm{~min}$ at $95^{\circ} \mathrm{C}$ for initial activation, followed by 40 cycles of the following protocol: denaturation at $94^{\circ} \mathrm{C}$ for $15 \mathrm{~s}$, annealing at $59^{\circ} \mathrm{C}$ for $15 \mathrm{~s}$, and elongation at $72^{\circ} \mathrm{C}$ for $15 \mathrm{~s}$ with detection of fluorescence products. The quantitative data were analyzed with LightCycler analysis software version 5.03 (Roche Diagnostics Japan). The expression levels of GLI genes were calculated as the ratio of GLI mRNA value to 
Table 1 Characteristics of the patients included in the study

Age (years)

\section{unatients included in the study}

$$
\text { Mean } \pm \text { SD (range) }
$$

Gender

Male
Female

Cigarette smoking

Never smoked
Ex-smoker
Current smoker
Pack-year/Mean \pm SD (range)

Tumor differentiation

$\begin{array}{ll}\text { Well } & 16 \\ \text { Moderate } & 53 \\ \text { Poor } & 32 \\ \text { Unknown } & 1\end{array}$

Tumor stage

$\begin{array}{ll}\text { II } & 3 \\ \text { III } & 60 \\ \text { IV } & 11\end{array}$

Operation method

$$
\begin{aligned}
& \text { Pneumonectomy } \\
& \text { Bilobectomy } \\
& \text { Lobectomy } \\
& \text { Segmentectomy } \\
& \text { Partial resection }
\end{aligned}
$$

Numbers ( $n$ )

Percent (\%)

64.8

68

34

34

33.3

20

19.6

48

47.1

36.6

$\pm 36.8(0-180)$

16

15.7

$53-52.0$

$32 \quad 31.4$

1

31

30.4

60

58.8

$11 \quad 10.8$

Complete resection

$\begin{array}{ll}\text { Yes } & 77 \\ \text { No } & 25\end{array}$

1.0

1.0

81.4

8.8

7.8

8

Preoperative chemotherapy

$$
\text { Yes }
$$

Postoperative chemotherapy

$\begin{array}{ll}\text { Yes } & 74\end{array}$

No

Radiotherapy to thorax (chest wall or mediastinum) ${ }^{a}$

$$
\text { Yes (Pre/Post) }
$$

No

EGFR gene mutation status

$$
\begin{aligned}
& \text { Wild-type } \\
& \text { Mutation (+) } \\
& \text { Unknown }
\end{aligned}
$$

Recurrence $^{\text {b }}$ 
Table 1 Characteristics of the patients included in the study (Continued)

\author{
Prognosis \\ Dead \\ ${ }^{a}$ Not including palliative radiotherapy. \\ bIncluding residual tumor after surgery. \\ SD: standard deviation. \\ GAPDH mRNA value, and are expressed as median and \\ mean \pm standard deviation.
}

\section{Statistical analysis}

Relationships between each pair of mRNA expression were estimated by calculating the Spearman's rank correlation coefficient $\left(r_{s}\right)$. Pairwise comparisons of postoperative survival of each GLI low and high groups were compared using the Mann-Whitney U test. Survival curves were evaluated by the Kaplan-Meier method, and cumulative survival data were compared using the logrank test. Multivariate analysis of prognostic factors was performed by the Cox proportional hazard model. Differences were considered significant when $P<0.05$. All statistical analyses were performed using StatMate IV software version 4.01 (ATMS, Tokyo, Japan) and JMP software version 8 (SAS Institute Japan, Tokyo, Japan).

\section{Results}

\section{GLI1, GLI2, and GLI3 mRNA were expressed in almost all} advanced lung adenocarcinoma tissues

GLI1 and GLI3 mRNA expression was detected in all 102 samples, whereas GLI2 mRNA was detected in 99 samples. The level of GLI1 mRNA (normalized and expressed as a ratio to $G A P D H$ mRNA) ranged from $2.35 \times 10^{-6}$ to $1.03 \times 10^{-1}$ (median, $3.03 \times 10^{-4}$; mean \pm standard deviation, $\left.3.97 \times 10^{-3} \pm 1.51 \times 10^{-2}\right)$; GLI2 mRNA level was 0 to $1.01 \times 10^{-2}\left(1.25 \times 10^{-3}, 1.78 \times 10^{-3} \pm 1.86 \times\right.$ $\left.10^{-3}\right)$; and GLI3 mRNA level was $7.68 \times 10^{-5}$ to $2.42 \times 10^{-1}$ $\left(1.07 \times 10^{-2}, 2.23 \times 10^{-2} \pm 3.93 \times 10^{-2}\right)$. The three GLI mRNA expression levels in all tissue samples are shown in Figure 1. Wide variations were observed in GLI1 and GLI3 mRNA levels in the primary tumor cohort, and based on these, we defined the upper $15 \%$ of patients as high GLI mRNA expression for each GLI gene (cutoff line; GLI1 mRNA: $2.49 \times 10^{-3}$, GLI2 mRNA: $3.71 \times 10^{-3}$, GLI3 mRNA: $3.46 \times$ $\left.10^{-2}\right)$.

\section{GLI1 and GLI3 mRNA expression levels were remarkably correlated}

By comparing GLI1, GLI2, and GLI3 mRNA expression levels, strong positive correlation was observed between GLI1 and GLI3 mRNA expression $\left(\mathrm{r}_{\mathrm{s}}=0.46, P<0.001\right)$ (Figure 2), whereas no such relations were found between GLI2 and GLI1 or GLI3 mRNA expression levels. Even with exclusion of the four observed outliers $(\mathrm{n}=$
98), strong positive correlation was also found between GLI1 and GLI3 mRNA expression $\left(\mathrm{r}_{\mathrm{s}}=0.40, P<0.001\right)$.

\section{GLI1 and GLI3 mRNA expression reflected postoperative patient survival}

There were statistically significant differences in postoperative survival between GLI1/GLI3 low and high mRNA expression groups (GLI1 mRNA: $P<0.001$; GLI3 mRNA: $P<0.001)$. Survival curves for each high/low GLI mRNA expression groups are presented in Figure 3. Five-year overall survival (OAS) rates in the GLI1 mRNA low and high groups were $41.7 \%$ and $20.0 \%$, and those in the GLI3 mRNA low and high groups were $43.1 \%$ and $13.3 \%$, respectively. Higher GLI1 and GLI3 mRNA expressing tumors in advanced lung adenocarcinoma patients were correlated with significantly worse overall survival rates than lower expression groups (GLI1 mRNA: $P=0.0074$, hazard ratio $(\mathrm{HR})=2.2(95 \%$ confidence interval: 1.4-6.9); GLI3 mRNA: $P=0.0062$, HR = 2.2 (1.4-6.6)). Similarly, 5-year disease-free survival (DFS) rates in the GLI1 mRNA low and high groups were $22.9 \%$ and $7.5 \%(P=0.086 ; \mathrm{HR}=1.7 \quad(0.91-3.9))$, and those in the GLI3 mRNA low and high groups were $23.2 \%$ and $6.7 \%(P=0.0027$; HR $=2.3(1.5-7.1))$, respectively. With regard to GLI2 mRNA expression, no statistical significance was observed between high and low expression groups (OAS: $P=0.32$; DFS: $P=0.93$ ).

Higher GLI1 mRNA expression was correlated with significantly worse prognosis especially in stage III-IV lung adenocarcinoma patients

Subset analysis of patients with stage III-IV lung adenocarcinoma $(\mathrm{n}=71)$ showed significantly worse clinical outcomes in both the higher GLI1 and GLI3 mRNA expression groups. In this cohort, 5-year OAS rates in the GLI1 mRNA low and high groups were $34.0 \%$ and $0 \%$, respectively $(P=0.0012, \mathrm{HR}=2.8(1.9-13.5))$, and 5-year DFS rates in these groups were $18.3 \%$ and $0 \%$, respectively $(P=0.027, \mathrm{HR}=2.1(1.1-7.2))$. Although the difference in OAS between the GLI3 mRNA expression groups was marginal (low, 33.4\% vs. high, $7.7 \%, P=$ $0.057)$, 5-year DFS rates were statistically different between GLI3 mRNA low and high groups (low, 17.6\% vs. high, $7.7 \%, P=0.030, \mathrm{HR}=1.9(1.1-5.3))$. Survival curves are presented in Figure 4. 
GLI1 mRNA expression

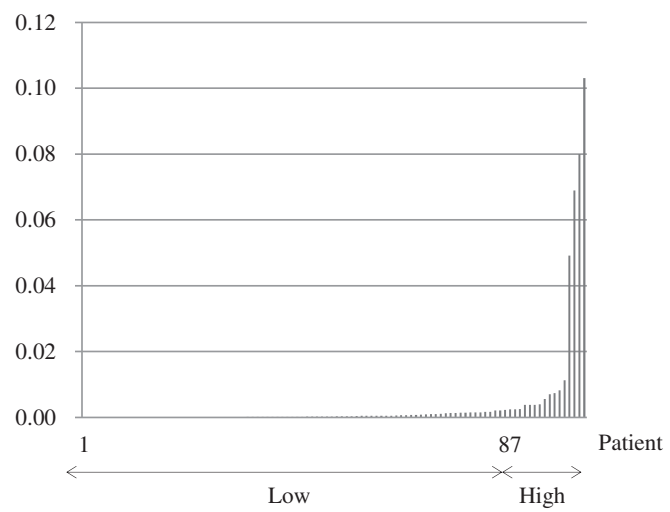

GLI3 mRNA expression

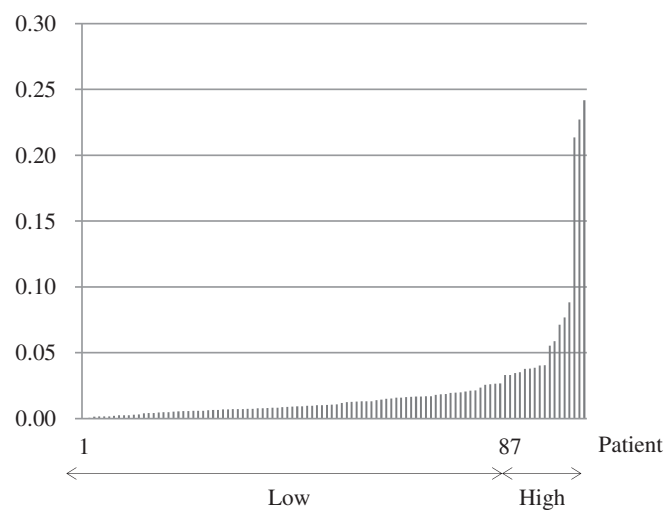

GLI2 mRNA expression

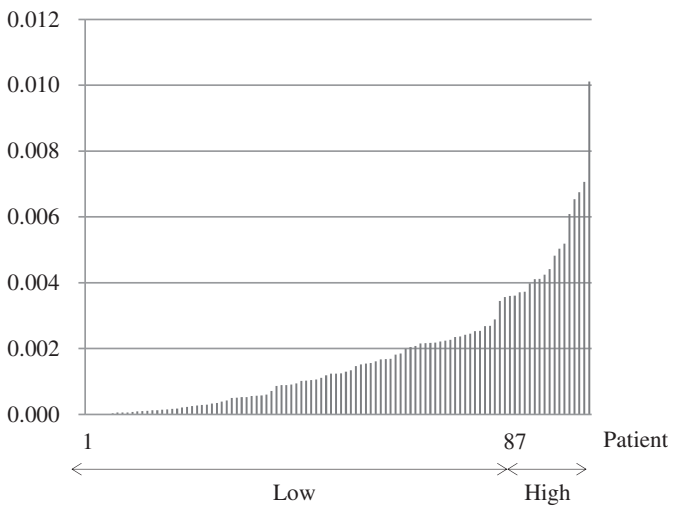

Figure $1 \mathrm{GLI}$ mRNA expression in stage II-IV lung adenocarcinoma patients. The levels of GLI1, GLI2, and GLI3 mRNA expression were measured by quantitative real-time polymerase chain reaction in stage II-IV lung adenocarcinoma samples. The three GLI mRNA were detected in all 102 samples, except three patients who were negative for GLI2. Wide variations were observed in GL/1 and GL/3 mRNA levels. The top 15\% of patients with the highest GLI expression were defined as the higher expression group in each category. Each mRNA value was expressed as a ratio to GAPDH mRNA (internal control).

Higher GLI1 mRNA expression was an independent prognostic factor in advanced lung adenocarcinoma The results of multivariate analyses for each clinicopathological parameter are presented in Table 2. Higher GLI1 mRNA expression was demonstrated to be an independent prognostic factor for poor patient prognosis $(P=0.0030$, $\mathrm{HR}=3.1(1.5-6.2)$ ) as well as tumor differentiation (well $v s$. poor) and tumor stage. No correlations were found for GLI2 and GLI3 mRNA expression with other clinicopathological features.

\section{Discussion}

Previous reports on $\mathrm{Hh}$ molecules have already provided us with convincing information on its etiologic contribution to NSCLC [16]. A large percentage of primary NSCLC cell lines have been shown to express $\mathrm{Hh}$ target genes including GLI1, indicating constitutive activation of the Hh pathway in NSCLC cell lines [17]. It was recently shown that disrupting the Hh pathway inhibited NSCLC proliferation in vitro and abrogated tumor growth in vivo [18]. In clinical samples, immunohistochemical analysis of tissue microarray have revealed significant correlation among the Hh molecules in early-stage NSCLC and of lymph node metastasis with nuclear GLI1 immunolocalization in lung adenocarcinoma $[19,20]$. However, the impact of Hh signaling on patient survival has not been previously reported in NSCLC.

In this study, expression of the three GLI genes was demonstrated in almost all cases in this cohort, although their expression levels varied widely. Interestingly, some lung adenocarcinoma samples showed relatively high GLI1 and GLI3 mRNA expression, and their expression patterns were considerably correlated. Although GLI1 is considered to be the major effector in Hh signaling, the role of GLI3 is still controversial. Whereas GLI3 acts mainly as a repressor in normal Hh signaling [21], some reports have suggested its activator capacity in oncogenesis [22-23]. The present study also provides evidence of 


\section{$P<0.001$}

\section{GLI3 mRNA}

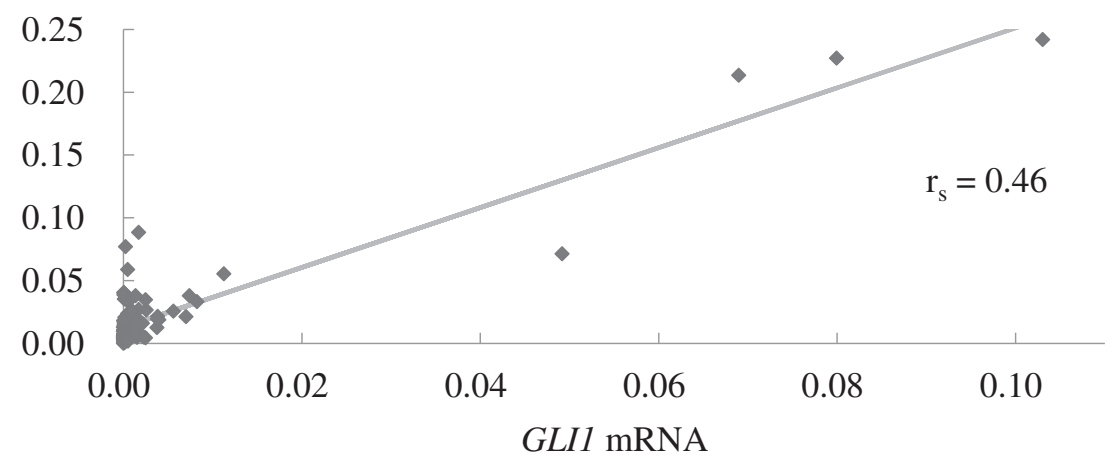

Figure 2 Relationship between GLI1 and GLI3 mRNA expression in stage II-IV lung adenocarcinoma patients. Pairwise comparisons of each GLI mRNA expression level showed that there was a strong positive correlation between GLI1 and GL/3 mRNA expression $\left(r_{s}=0.46, P\right.$ $<0.001)$. Statistical significance was estimated by calculating the Spearman's rank correlation coefficient $\left(r_{s}\right)$. Each mRNA value was expressed as a ratio to GAPDH mRNA (internal control). Bold value: statistically significant.
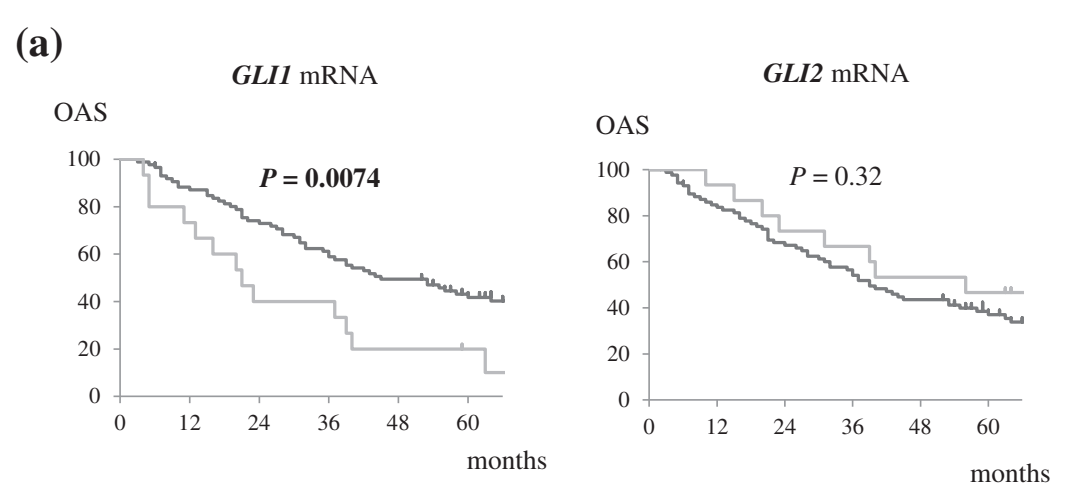

Low $(\mathrm{n}=87)$

(b)
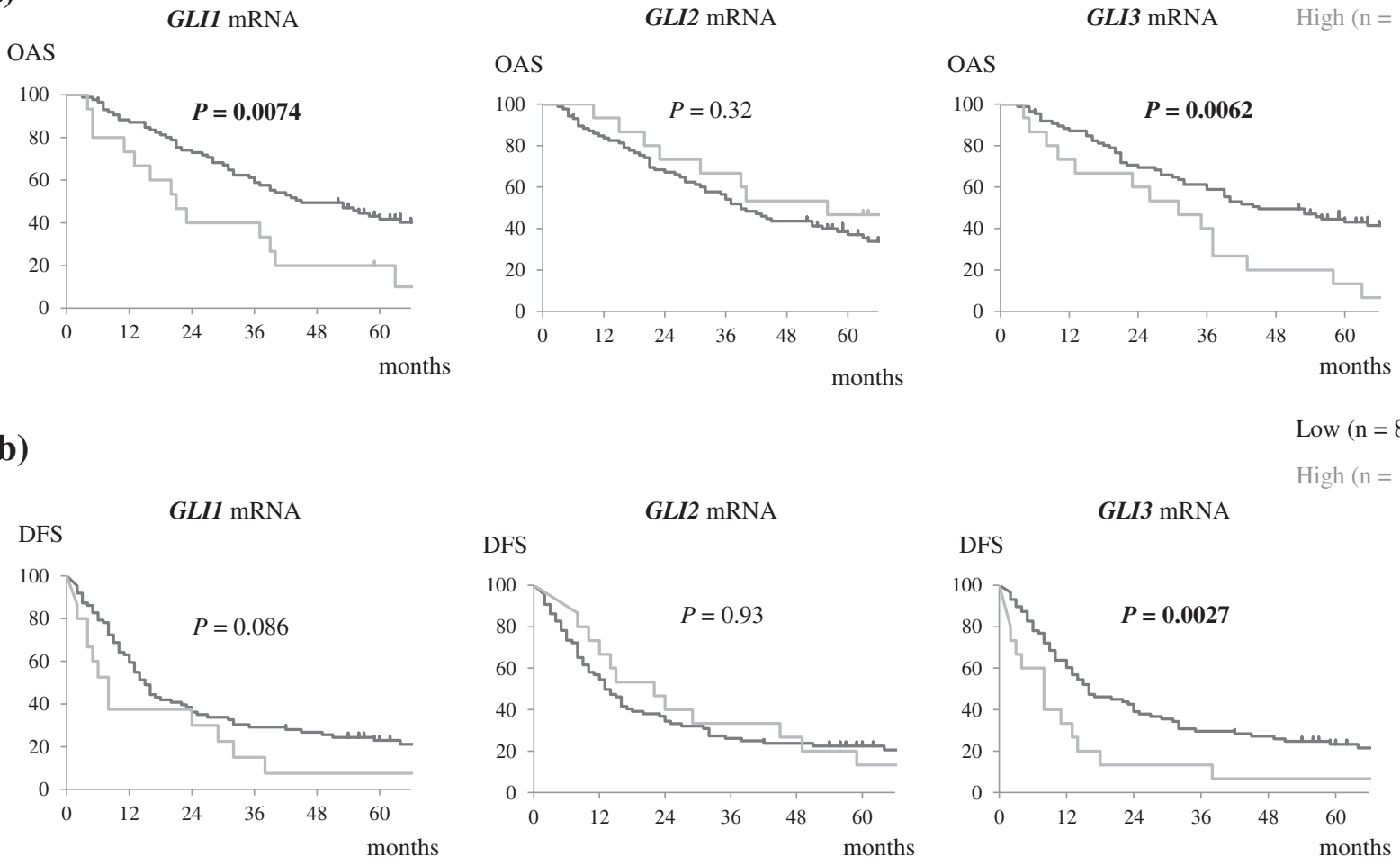

Figure 3 Survival curves according to GLI mRNA expression in stage II-IV lung adenocarcinoma patients. Kaplan-Meier analysis was performed on the basis of $G L I m R N A$ expression in all cohorts $(n=102)$. $P$ values were estimated by log-rank test. Tumors with higher expression (upper 15\%) of GLI1 or GLI3 mRNA were associated with poor survival in patients with stage II-IV lung adenocarcinoma. No statistical significance was observed for GLI2 mRNA expression. (a) Overall survival; (b) Disease-free survival. Ticks: censored cases; Bold values: statistically significant. 
(a)

OAS

GLII mRNA (stage III-IV)

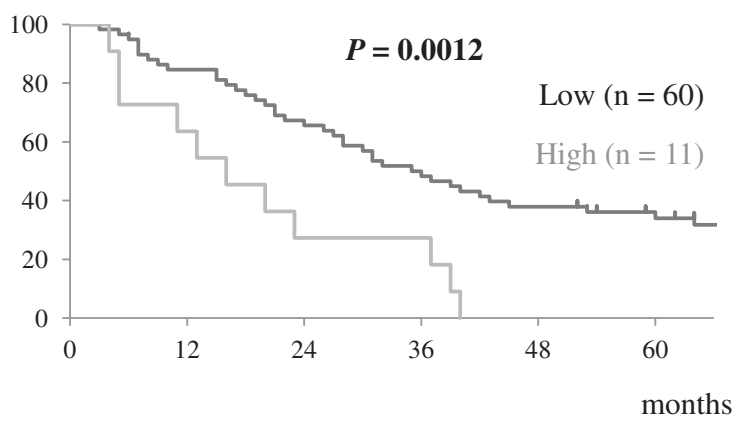

(b)

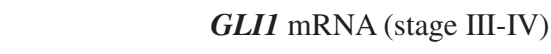

DFS

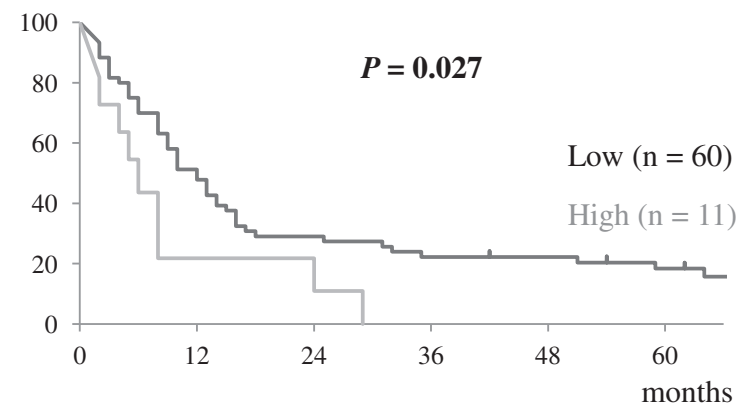

OAS $\quad$ GLI3 mRNA (stage III-IV)

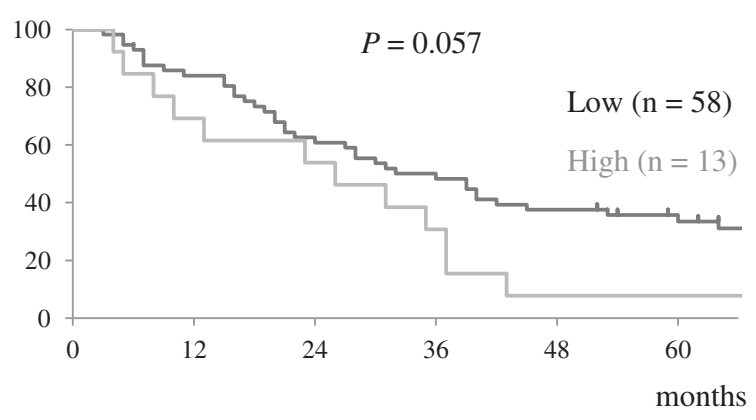

GLI3 mRNA (stage III-IV)

DFS

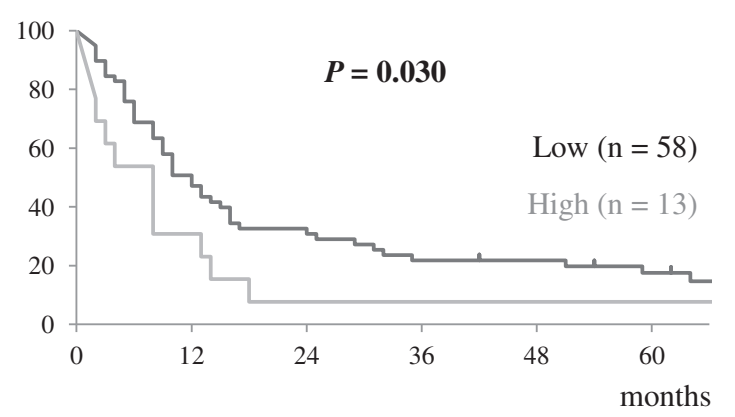

Figure 4 Survival curves according to GLI1 and GLI3 mRNA expression in stage III-IV lung adenocarcinoma patients. Kaplan-Meier analysis was performed on the basis of GLII and GLI3 mRNA expression in patients with stage III-IV lung adenocarcinoma. $P$ values were estimated by log-rank test. Higher GL/1 and GL/3 mRNA expression also correlated with unfavorable patient survival. (a) Overall survival; (b) Disease-free survival. Ticks: censored cases; Bold values: statistically significant.

the capacity of GLI3 to activate Hh signaling in concert with GLI1 in advanced lung adenocarcinoma. With regard to GLI2, very little is characterized about its expression in NSCLC, and only correlation between nuclear GLI2 with sonic Hh expression in lung squamous cell carcinoma has been reported [19]. From our research, no relation between GLI2 mRNA expression and GLI1 mRNA level, GLI3 mRNA level, or patient survival was detected, thus, the role of GLI2 in the pathogenesis of lung adenocarcinoma is still unclear.

While GLI1 is mainly regulated at the transcriptional level, GLI2 is considered as a latent transcriptional regulator that can be activated by Hh signaling. Modification of the N-terminus of GLI2 is a critical step in the regulation of the transcriptional activity of the protein [8]. This as well as the difference in cancer types may explain the discrepancies in GLI2 expression and patient outcomes between our results and previous ones [24]. Our research is based on the genetic expression of GLI, whereas for GLI2, it may be necessary to assess its functional protein level instead.
The mechanisms by which Hh signaling is involved in cancer pathogenesis are not uniform, and there are several different models of $\mathrm{Hh}$ signal transduction. Besides the most evident pattern of ligand-independent mutational $\mathrm{Hh}$ activation seen in basal cell carcinoma and medulloblastoma, ligand-dependent autocrine $\mathrm{Hh}$ activation in tumor cells has also been shown to be common in many cancers including NSCLC. In addition, ligand-dependent paracrine Hh signaling that involves the tumor microenvironment can lead to tumor development [25]. Crosstalk with other developmental cascades such as Wnt or Notch is also frequently observed [26]. This diversity of Hh signaling in cancer development in part explains the differences across cancer types $[27,28]$.

Previous reports on expression profiles of Hh-related molecules in NSCLC specimens had focused mainly on the estimation of protein levels by immunohistochemistry $[19,20]$, and their gene expression has not been thoroughly investigated. This study is unique in that thorough investigation was performed for the gene 
Table 2 Multivariate analysis of GLI1 mRNA expression and other clinicopathological variables for patient survival

\begin{tabular}{|c|c|c|c|c|}
\hline \multirow[t]{2}{*}{ Variables } & & \multicolumn{3}{|c|}{ Multivariate analysis } \\
\hline & & Hazard ratio & $95 \% \mathrm{Cl}$ & $P$-value ${ }^{\text {a }}$ \\
\hline \multicolumn{5}{|c|}{ GL/1 mRNA expression } \\
\hline & Low & 1 & & 0.0030 \\
\hline & High & 3.1 & $1.5-6.2$ & \\
\hline \multicolumn{5}{|l|}{ Age (years) } \\
\hline & $\leq 65$ & 1 & & 0.23 \\
\hline & $>65$ & 1.3 & $0.83-2.2$ & \\
\hline \multicolumn{5}{|l|}{ Gender } \\
\hline & Male & 1 & & 0.86 \\
\hline & Female & 0.92 & $0.37-2.2$ & \\
\hline \multicolumn{5}{|c|}{ Cigarette smoking } \\
\hline & Never smoked & 1 & & 0.69 \\
\hline & Smoker (ex or current) & 1.2 & $0.48-3.1$ & \\
\hline \multicolumn{5}{|c|}{ Tumor differentiation } \\
\hline & Well & 1 & & \\
\hline & Moderately & 1.7 & $0.83-3.6$ & 0.16 \\
\hline & Poorly & 2.5 & $1.1-5.8$ & 0.030 \\
\hline \multicolumn{5}{|c|}{ Tumor stage } \\
\hline & $\|$ & 1 & & \\
\hline & III & 2.5 & $1.5-4.5$ & $<0.001$ \\
\hline & IV & 4.2 & $1.7-9.8$ & 0.0027 \\
\hline \multicolumn{5}{|c|}{ EGFR gene mutation status } \\
\hline & Wild-type & 1 & & \\
\hline & Mutation (+) & 1.1 & $0.58-2.0$ & 0.77 \\
\hline \multicolumn{5}{|c|}{ Pre/postoperative chemo- and/or radiotherapy } \\
\hline & No & 1 & & \\
\hline & Yes & 0.67 & $0.33-1.4$ & 0.29 \\
\hline
\end{tabular}

*Cox's proportional hazard model.

$\mathrm{Cl}$ : confidence interval.

Bold values are statistically significant.

expression of all three GLI family members, which enabled us to directly compare their levels in clinical samples and to reveal the unexpected correlation between GLI1 and GLI3 mRNA expression. Interestingly, some GLI1/GLI3 highly expressing tumors (in this cohort, defined as the upper 15th percentile of patients for each mRNA expression) showed significantly poorer patient prognosis in advanced lung adenocarcinoma. Although a statistically significant negative correlation between survival and GLI1 expression has been shown in breast [29], esophageal [30], colorectal [31], and bladder cancers [32], this is the first study to demonstrate a clinical impact of GLI1 on patient survival in lung adenocarcinoma. Our speculation was further supported by the multivariate analysis, which showed that GLI1 mRNA expression is an indicator for unfavorable prognosis. Although the independency of $\mathrm{Hh}$ molecule expression on patient survival has been previously shown in bladder and prostate cancers [32,33], we are the first to reveal that of GLI1 in lung adenocarcinoma, which is indicative of the involvement of $\mathrm{Hh}$ signaling in a subset of NSCLC. Investigation on GLI3 expression in tumor samples has been rare, and the possible clinical impact of GLI3 expression raised by our study needs further corroboration by additional research studies.

Irrespective of these novel observations, some limitations should be addressed in the present study. First, the validity of the cutoff of mRNA values was not ensured. Unfortunately, for our data, dichotomizing patients by either median or mean value of mRNA expression provided little information on survival difference, thus, we defined the upper $15 \%$ expression level as the cutoff. Further, patient backgrounds were diverse. Due to the retrospective nature of analysis of these advanced stage cancer cases, pre- or postoperative therapies were not 
standardized and the completeness of resection was not fully warranted (for example, in stage IV patients, operations were mainly performed for salvage or diagnosis). We believe that these limitations can be overcome by expanding patient numbers and/or careful selection of patients with similar clinical backgrounds. Additionally, analyzing the expression profiles of GLI proteins as well as that of other Hh molecules in this cohort would further facilitate the deepening of our understanding.

With the advent of small molecule Hh inhibitors, such as vismodegib [34,35], recent interest has focused on the clinical application of Hh inhibitors in various types of tumors harboring aberrantly activated Hh signaling $[25,36]$. Based on our results, Hh inhibition may be a good candidate treatment for advanced lung adenocarcinoma. Because a similar study on stage I-II lung adenocarcinoma did not show any significance on patient survival [19], this signaling pathway may be involved more in tumor progression rather than tumorigenesis, and disrupting $\mathrm{Hh}$ may be more efficacious in the advanced stages of lung adenocarcinoma. Further studies including analysis of the expression of other Hh molecules or on other histological types of NSCLC are necessary to provide extended support of our findings.

\section{Conclusions}

We found that GLI1, GLI2, and GLI3 mRNA were expressed in almost all advanced stage lung adenocarcinoma tissue samples, and strong correlation was observed between GLI1 and GLI3 mRNA expression. While GLI2 mRNA expression level was of little clinical significance, a subset of patients showing relatively high GLI1/GLI3 expression showed poorer patient survival. In particular, higher GLI1 mRNA expression was an independent prognostic factor for unfavorable prognosis. This is the first report to describe the clinical involvement of the GLI family of genes in advanced lung adenocarcinoma, and these results suggest that Hh signal inhibition is a good candidate therapeutic target for advanced stage lung adenocarcinoma, which provide an impetus for further investigations on the Hh signaling in NSCLC.

\section{Abbreviations}

Cl: Confidence interval; DFS: Disease-free survival; GAPDH: Glyceraldehyde-3phosphate dehydrogenase; Hh: Hedgehog; HR: Hazard ratio; NSCLC: Nonsmall cell lung cancer; OAS: Overall survival; $r_{s}$ : Spearman's rank correlation coefficient; SD: Standard deviation.

\section{Competing interests}

The authors declare that they have no competing interests.

\section{Authors' contributions}

Ml designed the study, carried out the experiments, performed the statistical analysis, and wrote the manuscript. NI, TS, and KS made substantial contributions to the collection of clinical samples and the preparation of the materials. SM provided the clinical data and expertise in experimental techniques. HD supervised the entire study and gave final approval of the version to be published. All authors have read and approved the final manuscript.

\section{Acknowledgements}

We would like to thank Ms. Seiko Sakai and Ms. Yuuka Taketani for their excellent secretarial assistance. No outside funding was used for this project.

Received: 13 August 2013 Accepted: 20 July 2014

Published: 8 August 2014

References

1. Jemal A, Bray F, Center MM, Ferlay J, Ward E, Forman D: Global cancer statistics. CA Cancer J Clin 2011, 61:69-90.

2. Alberg AJ, Samet JM: Epidemiology of lung cancer. Chest 2003, 123(1 Suppl):21S-49S.

3. William WN Jr, Lin HY, Lee JJ, Lippman SM, Roth JA, Kim ES: Revisiting stage IIIB and IV non-small cell lung cancer: analysis of the surveillance, epidemiology, and end results data. Chest 2009, 136:701-709.

4. Shaw AT, Yeap BY, Solomon BJ, Riely GJ, Gainor J, Engelman JA, Shapiro GI, Costa DB, Ou SH, Butaney M, Salgia R, Maki RG, Varella-Garcia M, Doebele RC, Bang YJ, Kulig K, Selaru P, Tang Y, Wilner KD, Kwak EL, Clark JW, lafrate AJ, Camidge DR: Effect of crizotinib on overall survival in patients with advanced non-small-cell lung cancer harbouring ALK gene rearrangement: a retrospective analysis. Lancet Oncol 2011, 12:1004-1012.

5. Ruiz I, Altaba A, Sanchez P, Dahmane N: Gli and hedgehog in cancer: tumours, embryos and stem cells. Nat Rev Cancer 2002, 2:361-372.

6. Ingham PW, McMahon AP: Hedgehog signaling in animal development: paradigms and principles. Genes Dev 2001, 15:3059-3087.

7. Matise MP, Joyner AL: Gli genes in development and cancer. Oncogene 1999, 18:7852-7859.

8. Kasper M, Regl G, Frischauf AM, Aberger F: GLI transcription factors: mediators of oncogenic Hedgehog signalling. Eur J Cancer 2006, 42:437-445.

9. Yang L, Xie G, Fan Q, Xie J: Activation of the hedgehog-signaling pathway in human cancer and the clinical implications. Oncogene 2010, 29:469-481.

10. Teglund S, Toftgard R: Hedgehog beyond medulloblastoma and basal cell carcinoma. Biochim Biophys Acta 2010, 1805:181-208.

11. Watkins DN, Berman DM, Baylin SB: Hedgehog signaling: progenitor phenotype in small-cell lung cancer. Cell Cycle 2003, 2:196-198.

12. Park KS, Martelotto LG, Peifer M, Sos ML, Karnezis AN, Mahjoub MR, Bernard K, Conklin JF, Szczepny A, Yuan J, Guo R, Ospina B, Falzon J, Bennett S, Brown TJ, Markovic A, Devereux WL, Ocasio CA, Chen JK, Stearns T, Thomas RK, Dorsch M, Buonamici S, Watkins DN, Peacock CD, Sage J: A crucial requirement for hedgehog signaling in small cell lung cancer. Nat Med 2011, 17:1504-1508.

13. Vestergaard J, Pedersen MW, Pedersen N, Ensinger C, Tumer Z, Tommerup $\mathrm{N}$, Poulsen HS, Larsen LA: Hedgehog signaling in small-cell lung cancer: frequent in vivo but a rare event in vitro. Lung Cancer 2006, 52:281-290.

14. Sobin L, Gospodarowicz M, Wittekind C: TNM Classification of Malignant Tumours (UICC International Union Against Cancer). 7th edition. Oxford: Wiley-Blackwell Co.; 2009.

15. Travis WD, Brambilla E, Muller-Hermelink HK, Harris CC: Pathology \& Genetics of Tumours of the Lung, Pleura, Thymus and Heart (World Health Organization Classification of Tumours), Volume Volume 10. Lyon: IARC Press; 2004.

16. Velcheti V, Govindan R: Hedgehog signaling pathway and lung cancer. J Thorac Oncol 2007, 2:7-10.

17. Yuan Z, Goetz JA, Singh S, Ogden SK, Petty WJ, Black CC, Memoli VA, Dmitrovsky $E$, Robbins DJ: Frequent requirement of hedgehog signaling in non-small cell lung carcinoma. Oncogene 2007, 26:1046-1055.

18. Rodriguez-Blanco J, Schilling NS, Tokhunts R, Giambelli C, Long J, Liang Fei D, Singh S, Black KE, Wang Z, Galimberti F, Bejarano PA, Elliot S, Glassberg MK, Nguyen DM, Lockwood WW, Lam WL, Dmitrovsky E, Capobianco AJ, Robbins DJ: The hedgehog processing pathway is required for NSCLC growth and survival. Oncogene 2013, 32:2335-2345.

19. Raz G, Allen KE, Kingsley C, Cherni I, Arora S, Watanabe A, Lorenzo CD, Edwards VD, Sridhar S, Hostetter G, Weiss GJ: Hedgehog signaling pathway molecules and ALDH1A1 expression in early-stage non-small cell lung cancer. Lung Cancer 2012, 76:191-196. 
20. Gialmanidis IP, Bravou V, Amanetopoulou SG, Varakis J, Kourea H, Papadaki $\mathrm{H}$ : Overexpression of hedgehog pathway molecules and FOXM1 in non-small cell lung carcinomas. Lung Cancer 2009, 66:64-74

21. Wang B, Fallon JF, Beachy PA: Hedgehog-regulated processing of Gli3 produces an anterior/posterior repressor gradient in the developing vertebrate limb. Cell 2000, 100:423-434.

22. Iwasaki H, Nakano K, Shinkai K, Kunisawa Y, Hirahashi M, Oda Y, Onishi H, Katano M: Hedgehog Gli3 activator signal augments tumorigenicity of colorectal cancer via upregulation of adherence-related genes. Cancer Sci 2013, 104:328-336.

23. Kang HN, Oh SC, Kim JS, Yoo YA: Abrogation of Gli3 expression suppresses the growth of colon cancer cells via activation of p53. Exp Cell Res 2012, 318:539-549.

24. Im S, Choi HJ, Yoo C, Jung JH, Jeon YW, Suh YJ, Kang CS: Hedgehog related protein expression in breast cancer: gli-2 is associated with poor overall survival. Korean J Pathol 2013, 47:116-123.

25. Gupta S, Takebe N, Lorusso P: Targeting the hedgehog pathway in cancer. Ther Adv Med Oncol 2010, 2:237-250.

26. Geissler K, Zach O: Pathways involved in drosophila and human cancer development: the notch, hedgehog, wingless, runt, and trithorax pathway. Ann Hematol 2012, 91:645-669.

27. Bertrand FE, Angus CW, Partis WJ, Sigounas G: Developmental pathways in colon cancer: crosstalk between WNT, BMP, hedgehog and notch. Cell Cycle 2012, 11:4344-4351.

28. Santoni M, Burattini L, Nabissi M, Morelli MB, Berardi R, Santoni G, Cascinu S: Essential role of Gli proteins in glioblastoma multiforme. Curr Protein Pept Sci 2013, 14:133-140.

29. ten Haaf A, Bektas N, von Serenyi S, Losen I, Arweiler EC, Hartmann A, Knuchel R, Dahl E: Expression of the glioma-associated oncogene homolog (GLI) 1 in human breast cancer is associated with unfavourable overall survival. BMC Cancer 2009, 9:298.

30. Mori Y, Okumura T, Tsunoda S, Sakai Y, Shimada Y: Gli-1 expression is associated with lymph node metastasis and tumor progression in esophageal squamous cell carcinoma. Oncology 2006, 70:378-389.

31. Ding YL, Zhou Y, Xiang L, Ji ZP, Luo ZH: Expression of glioma-associated oncogene homolog 1 is associated with invasion and postoperative liver metastasis in colon cancer. International journal of medical sciences 2012, 9:334-338.

32. He HC, Chen JH, Chen XB, Qin GQ, Cai C, Liang YX, Han ZD, Dai QS, Chen YR, Zeng GH, Zhu JG, Jiang FN, Zhong WD: Expression of hedgehog pathway components is associated with bladder cancer progression and clinical outcome. Pathol Oncol Res 2012, 18:349-355.

33. Azoulay S, Terry S, Chimingqi M, Sirab N, Faucon H, Gil Diez De Medina S, Moutereau S, Maille P, Soyeux P, Abbou C, Salomon L, Vacherot F, de la Taille A, Loric S, Allory Y: Comparative expression of hedgehog ligands at different stages of prostate carcinoma progression. J Pathol 2008, 216:460-470.

34. Henkin Rl: Vismodegib in advanced basal-cell carcinoma. N Engl J Med 2012, 367:970. Author reply 970-971.

35. Berlin J, Bendell JC, Hart LL, Firdaus I, Gore I, Hermann RC, Mulcahy MF, Zalupski MM, Mackey HM, Yauch RL, Graham RA, Bray GL, Low JA: A randomized phase II trial of vismodegib versus placebo with FOLFOX or FOLFIRI and bevacizumab in patients with previously untreated metastatic colorectal cancer. Clin Cancer Res 2013, 19:258-267.

36. Neal JW, Sequist LV: Exciting new targets in lung cancer therapy: ALK, IGF-1R, HDAC, and Hh. Curr Treat Options in Oncol 2010, 11:36-44.

\section{Submit your next manuscript to BioMed Central and take full advantage of:}

- Convenient online submission

- Thorough peer review

- No space constraints or color figure charges

- Immediate publication on acceptance

- Inclusion in PubMed, CAS, Scopus and Google Scholar

- Research which is freely available for redistribution

Submit your manuscript at www.biomedcentral.com/submit 